\title{
Combined phacoemulsification and transpupillary drainage of silicone oil: results and complications
}

\author{
Alex Assi, Simon Woodruff, Eustratios Gotzaridis, Catey Bunce, Paul Sullivan
}

\begin{abstract}
Aim-To review retrospectively 74 consecutive cases of combined phacoemulsification and transpupillary drainage of silicone oil.

Methods-Candidate patients for intraocular silicone oil removal and cataract extraction underwent combined phacoemulsification and transpupillary drainage of silicone oil through a planned posterior capsulorrhexis and without the use of a pars plana infusion line.

Results-The retina remained attached in $59(79.7 \%)$ patients postoperatively. In this success group, the postoperative visual acuity improved in $42(71.2 \%)$ patients. There was no association between age, duration of silicone oil tamponade, preoperative diagnosis, macular status or number and nature of previous surgery, and the incidence of redetachment following silicone oil removal.

Conclusion-Combined phacoemulsification and transpupillary drainage of silicone oil is a safe and reliable technique that offers the main advantage of diminished surgical trauma.

(Br f Ophthalmol 2001;85:942-945)
\end{abstract}

Silicone oil serves as intraocular tamponade after pars plana vitrectomy and is widely used for the treatment of complex retinal detachments. Because the incidence and severity of its complications such as cataract and glaucoma increase with its intraocular duration ${ }^{1-3}$ it is recommended that silicone oil is removed as soon as its tamponade effect is no longer needed. ${ }^{4-6}$ Cataracts can develop in nearly all eyes in which the silicone oil remains in situ for a few months ${ }^{7-10}$ and up to $60 \%$ of lenses that appear relatively clear at the time of silicone oil removal will also develop a clinically significant cataract after 2 years. ${ }^{1011}$

Removal of oil can be combined with either extracapsular cataract extraction ${ }^{12} 13$ or phacoemulsification. Various techniques of combined phacoemulsification and oil removal have been described ${ }^{14-17}$ and a less invasive method obviating the use of a pars plana infusion line and based on hydrodynamic expression of the oil through a planned posterior capsulorrhexis has recently been recommended and adopted. ${ }^{18} 19$ This simplified method described in small series offers the advantages of quicker and less invasive surgery with faster visual rehabilitation. Theoretical disadvantages lie in the violation of the posterior capsule integrity. This study was conducted to assess the outcome of 74 consecutive patients undergoing this particular technique of combined clear corneal phacoemulsification, transpupillary silicone oil drainage, and intraocular lens implantation.

\section{Materials and methods}

Candidate patients for intraocular silicone oil removal and cataract extraction underwent combined phacoemulsification and transpupillary silicone oil drainage through a single superior corneal incision and without a pars plana infusion line. The surgery was performed under general anaesthetic in $65(88 \%)$ cases. At the end of a standard clear corneal phacoemulsification a central posterior capsulorrhexis with a diameter of approximately $3 \mathrm{~mm}$ was performed with forceps. A 20 gauge Rycroft canula was then introduced through the corneal incision and balanced salt solution (BSS) irrigated into the vitreous cavity. The stream of fluid directed through the posterior capsulorrhexis floats the silicone oil out through the pupil and the corneal incision and simultaneously replaces it with balanced salt solution. The infusion flow was continued until all oil was removed. The corneal section was then enlarged and a single piece poly(methylmethacrylate) (PMMA) intraocular lens (IOL) implanted in the capsular bag or in the ciliary sulcus in front of the anterior capsule as appropriate. The corneal wound was then closed with a 10.0 nylon suture and a subconjunctival injection of steroid and antibiotic was given at the end of each case. Care was taken throughout the procedure to avoid prolonged hypotony. All the patients were reviewed and examined on the first postoperative day and at regular intervals thereafter. Descriptive methods were used in statistical analysis except when assessing the association between categorical study factors and redetachment where Fisher's exact test was used.

\section{Results}

PATIENT CHARACTERISTICS

Seventy four patients (51 men, 23 women) with a mean age of 52.9 years (range 12-82 years) underwent combined phacoemulsification and silicone oil removal. The commonest indications for vitrectomy and silicone oil (1000 centistoke) injection were rhegmatogenous retinal detachment (RRD) with proliferative vitreoretinopathy (PVR) $(\mathrm{n}=45)$ and giant retinal tear $(\mathrm{GRT})(\mathrm{n}=22)$. Other indications are summarised in Table 1 . The macula was detached in 61 eyes $(82.4 \%)$. Twenty eight eyes (37.8\%) had silicone oil injection as a primary procedure and 46 eyes $(62.1 \%)$ had a history of at least one other retinal detachment operation before the placement of silicone oil. Additional surgical manoeuvres at the time of silicone oil injection 
Table 1 Preoperative features ( $n=74$ eyes)

\begin{tabular}{lll}
\hline Study factor & & Number (\% of $n$ ) \\
\hline Indications for silicone oil & RRD + PVR & $45(61)$ \\
& GRT + retinal detachment & $22(30)$ \\
& Traumatic retinal detachment & $4(5)$ \\
& Combined tractional and RRD & $2(3)$ \\
& RRD in acute retinal necrosis & $1(1)$ \\
Silicone oil injection & as a primary procedure & $28(38)$ \\
& as a second procedure & $33(45)$ \\
& as a third procedure & $10(13)$ \\
Macula-off & as a fourth procedure & $3(4.0)$ \\
Encirclement & & $61(82)$ \\
Retinectomy & & $14(19)$ \\
Prophylactic argon laser retinopexy & & $31(42)$ \\
\hline
\end{tabular}

Table 2 Anatomical and visual results ( $n=74$ eyes)

\begin{tabular}{|c|c|c|c|}
\hline Study factor & & Postoperative VA & $\begin{array}{l}\text { Number } \\
(\% \text { of } n)\end{array}$ \\
\hline \multirow[t]{2}{*}{ Remained attached } & Previously macula-off * & $\begin{array}{l}6 / 12 \text { or better } \\
6 / 18-6 / 60 \\
\text { Less than } 6 / 60\end{array}$ & $\begin{array}{r}7(15) \\
24(50) \\
16(33)\end{array}$ \\
\hline & Previously macula-on & $\begin{array}{l}6 / 12 \text { or better } \\
6 / 18-6 / 60 \\
\text { Less than } 6 / 60\end{array}$ & $\begin{array}{l}4(36) \\
7(64) \\
0(0)\end{array}$ \\
\hline Redetached & & $\begin{array}{l}6 / 12 \text { or better } \\
6 / 18-6 / 60 \\
\text { Less than } 6 / 60\end{array}$ & $\begin{array}{c}1(7) \\
0(0) \\
14(93)\end{array}$ \\
\hline
\end{tabular}

* Assessment of VA was not possible in one patient with learning difficulties

included epiretinal membrane (ERM) peel where appropriate, encirclement with a 276 hard silicone tyre $(\mathrm{n}=14)$ and relaxing retinectomy $(n=31)$. The median duration of silicone oil tamponade after pars plana vitrectomy was 5.0 months (range 3-19 months). The retina was clinically attached in all cases with no evidence of residual traction before silicone oil removal and $65(87.8 \%)$ eyes received preoperative prophylactic 360 degrees peripheral argon laser retinopexy (Table 1). The median length of patient follow up was 10 months (range $2-42$ months).

SURGICAL RESULTS

The retina remained attached in $59(79.7 \%)$ eyes following combined phacoemulsification and silicone oil removal. In this success group, the postoperative visual acuity (VA) improved in $42(71.2 \%)$ eyes, remained the same in nine $(15.2 \%)$ eyes and deteriorated in seven $(11.8 \%)$ eyes. Visual acuity could not be assessed in one of these patients with learning difficulties. The best corrected postoperative VA of the 48 eyes with previous macula-off retinal detachment was $6 / 12$ or better in seven eyes (14.6\%), between $6 / 60$ and $6 / 18$ in 24 eyes $(50 \%)$, and worse than $6 / 60$ in the remaining 16 eyes $(33.3 \%)$. The best corrected postoperative VA of the 11 eyes with previous macula-on retinal detachment was $6 / 12$ or better in four cases $(36.4 \%$ ) and between $6 / 18$ and $6 / 60$ in seven cases $(63.6 \%)$.

Fifteen eyes $(20.2 \%)$ sustained a recurrent retinal detachment after silicone oil removal (Table 2). Ten $(66.7 \%)$ occurred within the first 3 weeks and five $(33.3 \%)$ redetached after 1 month. Of the 15 failures, one eye was reattached with a cryo/buckle procedure and
11 required oil exchange with epiretinal membrane (ERM) peel and argon laser retinopexy as indicated. Three eyes were deemed inoperable due to massive ERM reproliferation and were treated symptomatically. The best corrected postoperative VA in this group of 15 eyes with redetachment was less than $6 / 60$ in all patients except for one case with a VA of 6/12 (Table 2).

\section{COMPLICATIONS}

Peroperative anterior capsulorhexis tear occurred in two eyes and necessitated conversion to extracapsular cataract extraction.

Postoperative subluxation of the lens within the capsular bag was observed in one eye and led to successful replacement of the $5 \mathrm{~mm}$ lens with a larger one.

Of the four eyes that developed persistent postoperative hypotony (intraocular pressure $<5 \mathrm{~mm} \mathrm{Hg}$ ) only one eye had a preoperative pressure of less than $10 \mathrm{~mm} \mathrm{Hg}(8 \mathrm{~mm} \mathrm{Hg})$. Three eyes redetached subsequently and one eye remained hypotonous but attached. Four other eyes developed raised postoperative intraocular pressure requiring medical treatment.

Excluding the group of eyes with recurrent retinal detachment, the postoperative visual acuity was limited by macular ERM proliferation in 13 eyes and non-specific macular scarring in 10 others. Cystoid macular oedema (CMO) occurred in two eyes and a macular hole in one eye. Posterior capsular thickening and contraction necessitated neodymiumyttrium-aluminium-garnet (YAG) laser capsulotomy in three cases. No cases of vitreous haemorrhage, choroidal haemorrhage, hyphaema, or postoperative keratopathy were seen in our patients. One eye only had a small residual symptomatic oil bubble postoperatively.

\section{Discussion}

\section{ADVANTAGES/DISADVANTAGES}

Our technique of silicone oil removal combined with phacoemulsification is similar to that described by Jonas et $a l^{18}$ except that we performed clear corneal incisions on all eyes. This combined approach is less invasive, averts conjunctival and scleral incisions, and avoids the complication of iris prolapse and loss of iris pigment epithelium as reported by some authors during silicone oil extrusion through a more posterior limbal wound. ${ }^{18}$ There is no interference with the pars plana and peripheral retina thus reducing the risk of peripheral iatrogenic retinal breaks, subretinal infusion, and vitreous or choroidal haemorrhage. ${ }^{18}$ In addition, it offers the advantages of shorter duration of surgery and quicker visual rehabilitation and reduces the need to perform a potentially difficult postoperative neodymiumYAG capsulotomy on a densely thickened posterior capsule. ${ }^{79121620}$ Drainage of silicone oil is usually complete reducing the risk of oil bubbles adhering to the posterior IOL surface and the only five patients who received a foldable silicone intraocular lens early in our series did not show any sign of complications. It is 
nevertheless recommended to avoid silicone IOL implants as silicone oil bubbles can irreversibly adhere to these artificial lenses. ${ }^{152122}$

The main disadvantage of this technique lies in the violation of the posterior capsule integrity. This offers the increased theoretical risk of capsular bag instability, postoperative retinal detachment, ${ }^{23}{ }^{24}$ and cystoid macular oedema. ${ }^{25}$ In case of the posterior capsulotomy becoming too large or irregular with inadequate capsular support, the IOL can be implanted in the ciliary sulcus in front of the anterior lens capsule. Conversely, the absence of vitreous traction in these eyes decreases the risk of postoperative retinal detachment and cystoid macular oedema. These are more likely to arise as a consequence of the complicated nature of the initial retinal detachment rather than be attributable to the method of oil removal. ${ }^{26}$ On the other hand, theoretical concerns exist regarding the damage caused to corneal endothelium by silicone oil flowing across the anterior chamber and out of the eye but no cases of postoperative clinically significant keratopathy were encountered in this series. In addition, by virtue of using one corneal incision only, this technique has the inconvenience of precluding additional necessary intraoperative posterior segment manoeuvres such as epiretinal membrane peeling.

\section{REDETACHMENT}

Redetachment rate after silicone oil removal has been reported to vary between $6 \%$ and $33 \% .^{5611} 14{ }^{27-31}$ Our redetachment rate $(20 \%)$ is similar to that reported above and in other smaller series using a similar technique of combined phacoemulsification and silicone oil removal. $^{15} 1819$ The incidence of new iatrogenic retinal breaks may be reduced by avoiding pars plana sclerotomies and the risk of redetachment may also be lessened by performing preoperative prophylactic 360 degree peripheral laser retinopexy. ${ }^{32}$ However, in the absence of similar preoperative characteristics and similar criteria for oil removal, valid comparison of redetachment rates between studies is difficult.

Age did not seem to influence the outcome of surgery in our series, as the mean age of patients who redetached after silicone oil removal (54.0 years, range 19-82) was similar to that of patients who remained attached (52.6 years, range $12-81$ ). There was also no association between the length of oil retention and the incidence of retinal redetachment as the median duration of silicone oil tamponade was equal in both groups (5.0 months). This failure to demonstrate a reduction in the redetachment rate after longer silicone oil tamponade is also confirmed by some studies 4527283034 but not others. ${ }^{29} 35$

Although the proportion of eyes with a giant retinal tear is higher in the redetachment group $(47 \%)$ compared with the success group $(25 \%)$, these data provide no evidence of a difference in preoperative diagnosis between the two groups as assessed by the Fisher's exact test $(p=0.19)$. This test also demonstrates no significant difference in the macular status of the detachment (on or off) before silicone oil injection between the two groups $(\mathrm{p}=1.0)$. Although the proportion of patients without preoperative 360 degree peripheral laser retinopexy is higher in the redetachment group $(20 \%)$ than in the success group $(10 \%)$, the Fisher's exact test demonstrates no significant difference in the number of patients with preoperative retinopexy between the two groups $(p=0.37)$. Moreover, we did not detect any association between previous encirclement $(\mathrm{p}=1.0)$ or retinectomy $(\mathrm{p}=0.77)$ and surgical outcome after silicone oil removal. Contrary to a previous report, ${ }^{29}$ a higher number of previous vitreoretinal procedures was not associated with a higher redetachment rate in our study $(\mathrm{p}=0.86)$ and this result is confirmed elsewhere. ${ }^{30}$ The fact that we have found little evidence of any association between the factors under study and redetachment may well be a reflection of the low power of this study.

\section{VISUAL ACUITY}

The silicone oil study confirmed that removal of silicone oil in anatomically successfully operated eyes significantly increases the likelihood of improved visual acuity in eyes after surgery for severe PVR. ${ }^{4}$ The postoperative visual acuity improved in $42(71.2 \%)$ of 59 successfully operated eyes in our series, remained the same in nine $(15.2 \%)$ eyes and deteriorated in seven $(11.8 \%)$ eyes. This incidence of postoperative visual acuity deterioration is similar to that reported by other authors ${ }^{11}{ }^{30}$ and has been attributed to maculopathy (hypotony, ERM, CMO and nonspecific scarring) in all these cases. Postoperative visual acuity may be improved by epiretinal membrane peel at the time of surgery. ${ }^{4}$ On the other hand, $14(93.3 \%)$ redetached eyes in this series failed to achieve a vision of $6 / 60$. This poor visual prognosis after redetachment is confirmed by other studies. ${ }^{29} 30$

\section{Conclusion}

Combined phacoemulsification and transpupillary silicone oil drainage through a planned posterior capsulorrhexis and without a pars plana infusion line is a simpler and less invasive technique that offers the advantages of diminished surgical trauma and reduced incidence of postoperative capsular thickening. We believe that this technique should be reserved for patients with a stable retina and closed retinal breaks not in need of additional surgical manoeuvres at the time of oil removal.

1 Stenberg P Jr, Hatchell D, Foulks GN, et al. The effects of silicone oil on the cornea. Arch Ophthalmol 1985;103:90-4. 2 Abrams GW, Azen SP, Barr CC, et al. The incidence of corneal abnormalities in the Silicone Study report 7. Arch Ophthalmol 1995;113:764-9.

3 Barr CC, Lai MY, Lean JS, et al. Postoperative intraocular pressure abnormalities in the Silicone Study. Silicone Study report 4. Ophthalmology 1993;100:1629-35.

4 Hutton W, Azen SP, Blumenkranz MS, et al. The effects of silicone oil removal. Silicone study report 6. Arch Ophthalmol 1994;112:778-85.

5 Casswell AG, Gregor ZJ. Silicone oil removal II. Operative and postoperative complications. Br $\mathcal{F}$ Ophthalmol 1987;71: 898-902.

6 Zilis JD, McCuen BW, de Juan E, et al. Results of silicone oil removal in advanced proliferative vitreoretinopathy. $A m \mathcal{F}$ Ophthalmol 1989;108:15-21. 
7 Leaver PK, Grey RHB, Garner A. Silicone oil injection in the treatment of massive preretinal traction. II. Late

8 Lucke KH, Foerster MH, Laqua H. Long-term results of Lucke $\mathrm{KH}$, Foerster $\mathrm{MH}$, Laqua $\mathrm{H}$. Long-term results of
vitrectomy and silicone oil in 500 cases of complicated retivitrectomy and silicone oil in 500 cases of complicated reti

nal detachments. Am f Ophthalmol 1987;104:624-33. Federman Jay L, Schubert HD. Complications associated
with the use of silicone oil in 150 eyes after retina-vitreous with the use of silicone oil in 150 eyes
surgery. Ophthalmology 1988;95:870-6

10 Casswell AG, Gregor ZJ. Silicone oil removal I. The effect on the complications of silicone oil. Br f Ophthalmol 1987, 71:893-7.

11 Franks WA, Leaver PK. Removal of silicone oil. Rewards and penalties. Eye 1991;5:333-7.

12 Baer RM, Aylward WG, Leaver PK. Cataract extraction following vitrectomy and silicone oil tamponade. Eye 1995;9: 309-12.

13 Korobelnik JF, Waked N, Chauvaud D, et al. Chirurgie de la cataracte apres injection d'huile de silicone. $\mathcal{F}$ Fr Ophtalmol cataracte apres injectic

14 Larkin GB, Flaxel CJ, leaver PK. Phacoemulsification and silicone oil removal through a single corneal incision. Ophthalmology 1998;105:2023-7.

15 Tanner V, Haider A, Rosen P. Phacoemulsification and combined management of intraocular silicone oil. $f$ Cataract Refract Surg 1998;24:585-91.

16 Korobelnik JF, Alietta A, Hannouche D, et al. Interret du capsulorhexis posterieur au cours de l'intervention combinee phakoemulsisfication et ablation de l'huile de silicone. F Fr Ophtalmol 1998;21:649-53.

17 Frau E, Lautier-Frau M, Labetouille M, et al. Phacoemulsification combined with silicone oil removal through posterior capsulorrhexis. Br f Ophthalmol 1999;83:1406-7.

18 Jonas JB, Budde WM, Panda-Jonas S. Cataract surgery combined with transpupillary silicone oil removal through planned posterior capsulotomy. Ophthalmology 1998;105: planned $1234-8$.

19 Budde WM, Jonas JB, Papp A. Kataraktextraktion kombiniert mit transpupillarer silikonolablassung durch geplante 345-8.

20 Weinberger D, Kremer I, Lichter H, et al. Extracapsular cataract extraction and intraocular lens implantation in eyes filled with silicone oil. I Cataract Refract Surg 1996;22: 403-6.

21 Reeves PD, Yung CW. Silicone intraocular lens encapsulation by shrinkage of the capsulorhexis opening. 7 Cataract Refract Surg 1998;24:1275-6.
22 Apple DJ, Federman JL, Thaddeus JK, et al. Irreversible silicone oil adhesion to silicone intraocular lenses. Ophthalmology 1996;103:1555-62.

23 Tielsch JM, Legro MW, Cassard SD, et al. Risk factors for retinal detachment after cataract surgery. A populationbased case-control study. Ophthalmology1996;103:153745.

24 Kerrison JB, Marsh M, Stark WJ, et al. Phacoemulsification after retinal detachment surgery. Ophthalmology 1996;103: 216-9.

25 Steinert RF, Puliafito CA, Kumar SR, et al. Cystoid macular edema, retinal detachment and glaucoma after Nd:YAG posterior capsulotomy. Am f Ophthalmol 1991;112:373-80.

26 Jonas JB, Budde WM, Knorr HLJ. Timing of retinal detachment after removal of intraocular silicone oil tamponade. Am f Ophthalmol 1999;128:628-31.

27 Lesnoni G, Rossi T, Nistri A, et al. Long-term prognosis after removal of silicone oil. Eur f Ophthalmol 2000;10:605.

28 Pavlovic S, Dick B, Schmidt KG, et al. Langzeitergebnisse nach silikonolentfernung. Ophthalmologe 1995;92:672-6.

29 Scholda C, Egger S, Lakits A, et al. Retinal detachment after silicone oil removal. Acta Ophthalmol Scand 2000;78:1826 .

30 Scholda C, Egger S, Lakits A, et al. Silicone oil removal: results, risks and complications. Acta Ophthalmol Scand 1997;75:695-9.

31 Ruellan YM, Roussat B. Decollement de retine: tamponnement interne provisoire par huile de silicone apres vitrectomie. Resultats anatomiques et fonctionnels. $\mathcal{F}$ Fr Ophtalmol $1985 ; 8: 117-24$.

32 Tufail A, Schwartz SD, Gregor ZJ. Prophylactic argon laser retinopexy prior to removal of silicone oil: a pilot study. Eye 1997;11:328-30.

33 Le Mer Y, Renard Y, Ameline B, et al. Evolution a long terme des yeux operes avec succes de decollement de retine par vitrectomie et injection d'huile de silicone. Effet de l'ablation du tamponnement sur les complications. F Fr Ophtalmol 1992;15:331-6.

34 Nawrocki J, Ghoraba H, Gabel VP. Probleme der silikonolentfernung. Ein studie uber 63 konsekutive falle. Ophthalmologe 1993;90:258-63.

35 Kampik A, Hoing C, Heidenkummer HP. Problems and timing in the removal of silicone oil. Retina 1992;12:S1116 . 